\title{
SÉANCE DU 23 JUIN 1905
}

\author{
PrÉSIDENCE DE M. ED. BUREAU.
}

Il est donné lecture du procès-verbal de la précédente séance dont la rédaction est adoptée.

M. le Président a le regret d'annoncer le décès de M. de Poli. M. F. Camus prononce au sujet de cette perte les paroles suivantes :

J'ai le regret d'annoncer à la Société la mort récente de notre confrère Henri de Poli. Ancien officier de marine, M. de Poli avait recueilli un certain nombre de plantes pendant son séjour aux colonies, particulièrement dans l'Asie orientale. Il y contracta malheureusement les germes d'une cruelle maladie qui fit de la seconde moitié de sa vie un véritable martyre : depuis près de vingt-cinq ans, il était paralysé des deux jambes et affligé d'une surdité complète; mais il a conservé jusqu'à sa mort une grande activité cérébrale et une énergie peu commune. Ne pouvant travailler que dans son lit, il dut abandonner l'étude parfois encombrante des Phanérogames et tourna ses efforts vers la Bryologie. Grâce à ses relations dans le personnel de la marine, il obtint d'intéressants envois de Muscinées dans lesquels Bescherelle et M. Revauld trouvèrent des espèces nouvelles. Bien que l'état de sa santé lui interdit d'assister à nos séances, il s'intéressait vivement à la prospérité de la Société à laquelle il appartenait depuis de longues années. On permettra à l'un de ceux qui l'ont connu et apprécié de lui dire ici un dernier adieu.

Au nom de M. Bonnier, M. Lutz présente à l'Assemblée un ouvrage récent écrit en collaboration avec M. Leclerc du Sablon et intitulé Cours de botanique. M. le Président remercie les auteurs de ce don important '.

M. Gagnepain donne lecture de la Notice suivante :

\section{Notice sur Antoine Le Grand,}

$$
\text { PAR M. CH. FLAHAULT. }
$$

La mort d'A. Le Grand, survenue le 13 mars 1905, a attristé tous ceux qui, la veille encore, recevaient ses lettres empreintes de l'amour

1. Voir les Novyelies à la fin du numéro. 


\section{$2 \mathrm{BHL}$ Biodiversity Heritage Library}

1905. "Séance Du 23 Juin 1905." Bulletin de la Société botanique de France 52, 388-388. https://doi.org/10.1080/00378941.1905.10829170.

View This Item Online: https://www.biodiversitylibrary.org/item/8674

DOI: https://doi.org/10.1080/00378941.1905.10829170

Permalink: https://www.biodiversitylibrary.org/partpdf/160524

\section{Holding Institution}

Missouri Botanical Garden, Peter H. Raven Library

\section{Sponsored by}

Missouri Botanical Garden

\section{Copyright \& Reuse}

Copyright Status: Public domain. The BHL considers that this work is no longer under copyright protection.

This document was created from content at the Biodiversity Heritage Library, the world's largest open access digital library for biodiversity literature and archives. Visit BHL at https://www.biodiversitylibrary.org. 